\title{
Measurement of $k_{0}$ values for europium, lutetium and iridium at FRM II with a very well thermalized neutron spectrum
}

\author{
Xiaosong $\mathrm{Li}^{1}$ (1) $\cdot$ Robbert van Sluijs ${ }^{2} \cdot$ Gregory Kennedy $^{3}$
}

Received: 5 October 2020 / Accepted: 6 November 2020 / Published online: 6 January 2021

(C) The Author(s) 2021

\begin{abstract}
The $k_{0}$ values of 6 non- $1 / v$ nuclides $\left({ }^{152} \mathrm{Eu},{ }^{152 \mathrm{~m}} \mathrm{Eu},{ }^{154} \mathrm{Eu},{ }^{177} \mathrm{Lu},{ }^{192} \mathrm{Ir}\right.$ and $\left.{ }^{194} \mathrm{Ir}\right)$ were determined using the extended $\mathrm{H} \varnothing \mathrm{gdahl}$ formalism at the research reactor FRM II with very high $f$ values. Standards were irradiated in 4 channels at different local temperatures between $40{ }^{\circ} \mathrm{C}$ and $55^{\circ} \mathrm{C}$ measured using temperature sensitive irreversible labels. A good agreement with the recommended values was found for ${ }^{152} \mathrm{Eu},{ }^{154} \mathrm{Eu}$ and ${ }^{177} \mathrm{Lu}$ using the original $g\left(T_{\mathrm{n}}\right)$ factors by Gryntakis, however, the $k_{0}$ values for ${ }^{152 \mathrm{~m}} \mathrm{Eu}$ in this work were $7 \%$ higher. New $k_{0}$ values were also determined using the $g\left(T_{\mathrm{n}}\right)$ factors by Van Sluijs. Differences up to $6 \%$ were found for Eu isotopes compared with the recommended values. The recommended $k_{0}$ values for ${ }^{192} \mathrm{Ir}$ and ${ }^{194} \mathrm{Ir}$ could be confirmed using $g=1$. The theoretical $k_{0}$ values for ${ }^{177} \mathrm{Lu}$ were calculated using new nuclear data. They are up to $6 \%$ less than the recommended values. The present $k_{0}$ values determined in this work showed a similar trend. The influence of different $g\left(T_{\mathrm{n}}\right)$ factors on the determination of the $k_{0}$ values was investigated.
\end{abstract}

Keywords $k_{0}$ values $\cdot k_{0}$ NAA $\cdot g$ factors $\cdot$ Non- $1 / v$ nuclides $\cdot$ Westcott convention $\cdot$ Extended høgdahl formalism $\cdot$ Neutron temperature $\cdot$ Neutron activation analysis

\section{Introduction}

The $k_{0}$ NAA method was first developed with the Høgdahl convention, which treated the activation with both thermal and epithermal neutrons as a temperature independent static process describing very well the $(\mathrm{n}, \gamma)$ reactions of most nuclides with cross sections varying as $1 / v(v$ is the neutron velocity) in the thermal neutron energy region $[1,2]$. For a few so-called non- $1 / v$ nuclides, a modification using the Westcott convention [3] with consideration of the influence of the neutron temperature on the cross sections was introduced in the 1990s [4, 5], while the definition of the $k_{0}$ factor including the cross section at a neutron velocity of $2200 \mathrm{~m} \mathrm{~s}^{-1}$ (corresponding to a neutron temperature

Xiaosong Li

Xiaosong.li@frm2.tum.de

1 MLZ, Forschungs-Neutronenquelle Heinz-Maier-Leibnitz FRM II, Technische Universität München, Lichtenbergstraße 1, 85747 Garching, Germany

2 k0-ware, Schaesbergerweg 25, 6415 AB Heerlen, The Netherlands

3 Department of Engineering Physics, Polytechnique Montréal (Retired), Montréal, Canada
$T_{\mathrm{n}}$ at $20{ }^{\circ} \mathrm{C}$ ) remained unchanged. The Westcott $g\left(T_{\mathrm{n}}\right)$ factors were used for the correction of the cross section at any temperature.

For the determination of the $k_{0}$ values for the non- $1 / v$ nuclides, the local neutron temperature at the irradiation position must first be determined. As a temperature monitor, Lutetium was suggested since the beginning, because the thermal neutron capture cross section of the reaction ${ }^{176} \mathrm{Lu}(\mathrm{n}, \gamma){ }^{177} \mathrm{Lu}$ varies very strongly with the neutron temperature. In this case, the recommended $k_{0}$ values of ${ }^{177} \mathrm{Lu}$ were calculated using atomic and nuclear data, including the cross section at the neutron velocity of $2200 \mathrm{~m} \mathrm{~s}^{-1}$, from the 1980s [2]. For the experimental determination of the ${ }^{177} \mathrm{Lu} k_{0}$ value, the neutron temperature has to be measured in an independent way, e.g. by using temperature readings of the reactor moderator measured by thermocouples [6]. At FRM II, a method using irreversible thermometer labels was developed to measure the temperature at the irradiation positions in situ [7] and applied to determine the $k_{0}$ values of some non- $1 / v$ nuclides in this work.

The Westcott $g\left(T_{\mathrm{n}}\right)$ factors can be calculated from the neutron cross section $\sigma(E)$ values and have been updated several times since the 1960s [3, 8-11]. The latest update of the $g\left(T_{\mathrm{n}}\right)$ factors was the calculations of Van Sluijs et al. 
published in 2015 [11]. However, the $k_{0}$ values for most of the non-1/v nuclides were determined in the 1980s with the $g\left(T_{\mathrm{n}}\right)$ factors of the $1970 \mathrm{~s}$, above all with the $g\left(T_{\mathrm{n}}\right)$ factors published by Gryntakis and Kim in 1975 [8]. Due to the different input databases of $\sigma(E)$, e.g. ENDF/B or the European Activation File EAF and different algorithms, significant discrepancies of $g\left(T_{\mathrm{n}}\right)$ factors can be found for Lu and other non- $1 / v$ nuclides. These lead to different neutron temperatures determined by using the Lu standard and different $k_{0}$ values finally.

The here mentioned three elements Lu, Eu and Ir are very important elements in multi element analysis, especially in the geosciences and cosmochemistry. With $k_{0}$ NAA, Ir was usually determined by measuring the short-lived isotope ${ }^{194}$ Ir although its sensitivity is lower than that of the longlived ${ }^{192} \mathrm{Ir}$. Based on the calculation of the $g\left(T_{\mathrm{n}}\right)$ factors in the $1970 \mathrm{~s}$, the ${ }^{191} \operatorname{Ir}(\mathrm{n}, \gamma){ }^{192} \operatorname{Ir}$ reaction was considered as non$1 / v$ and no $k_{0}$ values had been measured for ${ }^{192}$ Ir until 2014 $[12,13]$. However, new calculations of $g\left(T_{\mathrm{n}}\right)$ factors seem to support the temperature independence of the ${ }^{191} \operatorname{Ir}(\mathrm{n}, \gamma){ }^{192} \mathrm{Ir}$ reaction $[10,11]$.

Also in 2014, an extended Høgdahl formalism retaining the classical parameters $\left(f, \alpha, Q_{0}\right)$ was developed to replace the spectral index and $s_{0}$ factor of the Westcott convention for the non- $1 / v$ isotopes [14]. Cimpan and Kennedy recently determined the $k_{0}$ and $Q_{0}$ values of Lu and Eu using this new formalism and the $g\left(T_{\mathrm{n}}\right)$ factors published by Holden [9] at a reactor with significant proportion of epi-thermal neutron flux [15]. However, they found large discrepancies between their results and the recommended values for Eu.

The research reactor FRM II with very well thermalized neutron flux can minimize the activation with the epi-thermal neutrons, so that the uncertainties of the determination can be reduced significantly. In the present work the $k_{0}$ values of $\mathrm{Lu}, \mathrm{Eu}$ and Ir were determined; however, due to the very high $f$ values, a determination of $Q_{0}$ values was not possible.

Conventionally, the $g\left(T_{\mathrm{n}}\right)$ factors are associated with the target nuclides of the $(\mathrm{n}, \gamma)$ reactions, whereas the $k_{0}$ values are associated with the product nuclides because they refer to a specific emitted gamma-ray. Similarly, non- $1 / v$ nuclides mean the target nuclides, but are also used to describe the product nuclides in $k_{0}$ NAA. We follow these conventions in this paper.

\section{Theory}

For the determination of non- $1 / v$ nuclides with NAA, the $k_{0}$ method was modified with the Westcott formalism. If the neutron temperature is measured, the mass fraction $\rho$ of an unknown element can be determined by the following formula neglecting the neutron self-shielding [5]:

$\rho=\frac{\left(\frac{N_{p}}{S D C t_{m}}\right)}{\left(\frac{N_{p}}{S D C w t_{m}}\right)^{*}} \frac{1}{k_{0}} \frac{g\left(T_{n}\right)^{*}+r(\alpha) \sqrt{T_{n} / T_{0}} s_{0}^{*}(\alpha)}{g\left(T_{n}\right)+r(\alpha) \sqrt{T_{n} / T_{0}} s_{0}(\alpha)} \frac{\varepsilon_{p}^{*}}{\varepsilon_{p}}$

where (*) is the co-irradiated comparator, $N_{\mathrm{p}}$ is the measured peak area, $S=1-\exp \left(-\lambda t_{\text {irr }}\right)$ with the decay constant $\lambda$ and the irradiation time $t_{\text {irr }}, D=\exp \left(-\lambda t_{\mathrm{d}}\right)$ with the decay time $t_{\mathrm{d}}, C=\left[1-\exp \left(-\lambda t_{\mathrm{m}}\right)\right] / \lambda t_{\mathrm{m}}$ with the measuring time $t_{\mathrm{m}} ; W$ and $w$ are sample and monitor mass, $g\left(T_{\mathrm{n}}\right)$ is the Westcott's $g$ factor, $T_{\mathrm{n}}$ is the neutron temperature, $r$ is the modified spectral index, $s_{0}$ is the modified reduced resonance integral to thermal cross section ratio, $\alpha$ is the epithermal spectrum shape parameter, $\varepsilon_{\mathrm{p}}$ is the full-energy peak efficiency. For a pure Maxwellian neutron spectrum, the epithermal index $r$ is equal to 0 [3].

A simplified extended version of the modified Høgdahl convention was introduced recently to replace the classical parameters of Westcott formalism with the conventional $k_{0}$ parameters [14]

$\rho=\frac{\left(\frac{N_{p}}{S D C t_{m}}\right)}{\left(\frac{N_{p}}{S D C w t_{m}}\right)^{*}} \frac{1}{k_{0}} \frac{1+Q_{0}^{*}(\alpha) / f}{g\left(T_{n}\right)+Q_{0}(\alpha) / f} \frac{\varepsilon_{p}^{*}}{\varepsilon_{p}}$

where ${ }^{197} \mathrm{Au}(*)$ is used as the comparator and treated as a $1 / v$-nuclide, $f$ is the thermal to epi-thermal flux ratio, $Q_{0}$ is the cross section ratio (resonance integral divided by cross section at $v=2200 \mathrm{~m} \mathrm{~s}^{-1}$ ). The $Q_{0}$ values of some non- $1 / v$ nuclides were determined by using this new modified version [15]. Table 1 shows the ranges of $Q_{0}$ values found in the literature [12-18]. For a modern reactor with a very well thermalized neutron spectrum, i.e. a very high $f$ value, the ratio of $Q_{0}(\alpha) / f$ is less than $0.3 \%$ for most nuclides [19]. Therefore, the above equations can be simplified further by replacing the activation term with just the $g\left(T_{\mathrm{n}}\right)$ factor for all non- $1 / v$ nuclides:

$\rho=\frac{\left(\frac{N_{p}}{S D C W_{m}}\right)}{\left(\frac{N_{p}}{S D C w t_{m}}\right)^{*}} \frac{1}{k_{0}} \frac{1}{g\left(T_{n}\right)} \frac{\varepsilon_{p}^{*}}{\varepsilon_{p}}$

Table 1 literature values of $Q_{0}$ [12-18]

\begin{tabular}{ll}
\hline Reaction & $Q_{0}$ literature \\
\hline${ }^{151} \mathrm{Eu}(n, \gamma){ }^{152 \mathrm{~m}} \mathrm{Eu}$ & $0.1-1.2$ \\
${ }^{151} \mathrm{Eu}(n, \gamma){ }^{152} \mathrm{Eu}$ & $0.5-1.36$ \\
${ }^{153} \mathrm{Eu}(n, \gamma){ }^{154} \mathrm{Eu}$ & $3.95-5.66$ \\
${ }^{176} \mathrm{Lu}(n, \gamma){ }^{177} \mathrm{Lu}$ & $1.67-3.59$ \\
${ }^{191} \mathrm{Ir}(n, \gamma){ }^{192} \mathrm{Ir}$ & $3.47-3.94$ \\
${ }^{193} \mathrm{Ir}(n, \gamma){ }^{194} \mathrm{Ir}$ & $12.0-13.4$ \\
\hline
\end{tabular}


Note that this simplified formula of the extended Høgdahl convention still has one difference from that of the Westcott formalism. The Westcott formula has $g\left(T_{n}\right)$ of the monitor in the numerator. With $g\left(T_{\mathrm{n}}\right)$ of ${ }^{197} \mathrm{Au}(\mathrm{n}, \gamma){ }^{198} \mathrm{Au}$ approximately 1.007 at typical research reactor moderator temperatures [4], there is a $0.7 \%$ difference between the two formulae.

This formula can be applied to determine the $k_{0}$ values, if standards with known concentration are used:

$k_{0}=\frac{\left(\frac{N_{p}}{S D C W \rho t_{m}}\right)}{\left(\frac{N_{p}}{S D C w t_{m}}\right)^{*}} \frac{1}{g\left(T_{n}\right)} \frac{\varepsilon_{p}^{*}}{\varepsilon_{p}}$

In this expression, the normally relevant parameters such as $f, Q_{0}(\alpha), \bar{E}_{r}$ (effective resonance energy) or $s_{0}(\alpha)$ have no influence on the calculation, which makes the determination of the $k_{0}$ values simpler and potentially more accurate.

It can be seen in Eq. 4 that the $k_{0}$ determination depends directly on the $g\left(T_{\mathrm{n}}\right)$ factor used. Figures $1-5$ show the Westcott $g\left(T_{\mathrm{n}}\right)$ factors for $\mathrm{Lu}$, Eu and Ir calculated by different authors $[3,8-11]$ in the temperature range between $20{ }^{\circ} \mathrm{C}$ and $100{ }^{\circ} \mathrm{C}$, which is the operating temperature range at most research reactors. The neutron cross section data $\sigma(E)$ from the ENDF database used for these $g\left(T_{\mathrm{n}}\right)$ calculations for ${ }^{176} \mathrm{Lu}$ and ${ }^{151} \mathrm{Eu}$ over a period of more than 50 years evolved over time, as shown in Fig. 6. The curves show also why ${ }^{176} \mathrm{Lu}$ is so sensitive on the thermal neutron temperature and why the $g\left(T_{\mathrm{n}}\right)$ factor of ${ }^{151} \mathrm{Eu}$ has a negative slope.

The $g\left(T_{\mathrm{n}}\right)$ factors can be fitted with a polynomial regression of $1^{\text {st }}$ or $2^{\text {nd }}$ order. In recent works, Van Sluijs et al. proposed fitting with a third-degree polynomial $[11,20]$. However, the difference is less than $0.1 \%$ within the temperature range considered here for most nuclides. Even for ${ }^{152} \mathrm{Eu}$, whose $g\left(T_{\mathrm{n}}\right)$ factors show a slight curvature, the maximum deviation can reach only $0.2 \%$ in the region between $60{ }^{\circ} \mathrm{C}$ and $70{ }^{\circ} \mathrm{C}$. In order to simplify the calculations, linear approximations were used in this work (Eq. 5) and the coefficients are given in Table 2.

$g\left(T_{n}\right)=a_{0}+a_{1} T_{n} / 1000$

For Lu, the $g\left(T_{\mathrm{n}}\right)$ factor lines in Fig. 1 are close to parallel and can be divided into two groups. The $g\left(T_{\mathrm{n}}\right)$ factors of Holden (1999) and Choi and Trkov (2007) are quite close to each other, although they used different input databases of ENDF/B-V and EAF-99, but they are about $4 \%$ higher than the other three $g\left(T_{\mathrm{n}}\right)$ data sets. This would lead to different results of the $k_{0}$ determination or temperature determination (up to $10^{\circ} \mathrm{C}$ ), if $\mathrm{Lu}$ is used as the temperature monitor [7]. Holden used in his 1999 paper the
ENDF/B-VI data base for all nuclides except for ${ }^{176} \mathrm{Lu}$. His $g$ factors for ${ }^{176} \mathrm{Lu}$ were still based on the older ENDF/B-V database. He mentioned the fact that databases evolve and thus lead to changes in any data like $g\left(T_{\mathrm{n}}\right)$ derived from them. The changes in the neutron cross sections $\sigma(E)$ for ${ }^{176} \mathrm{Lu}$ since ENDF/B-V, see Fig. 6, were the reason for the differences in the more recently calculated $g\left(T_{\mathrm{n}}\right)$ factors seen in Fig. 1. Surprisingly, the $g\left(T_{\mathrm{n}}\right)$ factors calculated by Van Sluijs et al. in 2015 using the new evaluated nuclear data of BNDF/B-VII.1 came back to the old factors calculated in the 1970s.

Large differences could be also found between the $g\left(T_{\mathrm{n}}\right)$ factors for ${ }^{151} \mathrm{Eu}$. Here, the $g\left(T_{\mathrm{n}}\right)$ factors by Van Sluijs et al. are significantly different from the others, up to $5 \%$ because the evaluated cross section data was changed after ENDF/B-VI. Gryntakis and Kim calculated the $g\left(T_{\mathrm{n}}\right)$ factors separately for the activation products ${ }^{152} \mathrm{Eu},{ }^{152 \mathrm{~m}} \mathrm{Eu}$ with different isomer yield ratios. However, the difference is about $1.5 \%$ between them. Other authors neglected this tiny difference because they based their calculations on evaluated data that did not contain this detailed information. For ${ }^{153} \mathrm{Eu}$, the influence of the temperature on the $g\left(T_{\mathrm{n}}\right)$ factors is not strong: all lines are quite flat. Therefore, ${ }^{153} \mathrm{Eu}$ was usually treated as a $1 / v$ nuclide. But the difference between the $g\left(T_{\mathrm{n}}\right)$ factors is more than $6 \%$.

${ }^{191}$ Ir was always treated as a non- $1 / v$ nuclide in the past. Obviously, the $g\left(T_{\mathrm{n}}\right)$ factor by Gryntakis and Kim with a deviation up to $4 \%$ from unity had a big influence on this decision at that time, when the $k_{0}$ method was launched in the 1980s. However, Holden considered both isotopes of $\mathrm{Ir}$ as $1 / v$ nuclides and did not calculate the $g\left(T_{\mathrm{n}}\right)$ factors for them. Westcott did not give the $g\left(T_{\mathrm{n}}\right)$ factors for both isotopes of Ir explicitly and seemingly gave the factors for the element Ir. Choi and Trkov and Van Sluijs et al. calculated the factors separately $[10,11]$; however, their results for ${ }^{191} \mathrm{Ir}$ are very close to unity. On the contrary, the $g\left(T_{\mathrm{n}}\right)$ factors for ${ }^{193}$ Ir show greater deviation from unity.

\section{Experimental}

$\mathrm{Lu}, \mathrm{Eu}$ and $\mathrm{Ir}$ standards for the determination of the $k_{0}$ values were prepared using $1000 \mathrm{mg} \mathrm{L}^{-1}( \pm 0.5 \%)$ certified ICP standard solutions CertiPUR $\AA$ manufactured by Merck. A $200 \mu \mathrm{L}$ aliquot of each standard was pipetted onto $0.1 \mathrm{~mm}$ thick round filter paper ( $\varnothing 16 \mathrm{~mm}$ ) directly on a balance during weighing. The filter papers were enclosed in PE bags after drying. The certified element concentrations were $(989 \pm 5) \mu \mathrm{g} \mathrm{g}^{-1}$ for $\mathrm{Lu},(986 \pm 4) \mu \mathrm{g} \mathrm{g}^{-1}$ for $\mathrm{Eu}$ and $(970 \pm 5) \mu \mathrm{g} \mathrm{g}^{-1}$ for Ir. Au-Al foils (IRMM-530R, $0.1003 \pm 0.0012 \%)$ as monitors and Lu-Al standard foils (IRMM-sp96091, 0.100 $\pm 0.002 * \% \mathrm{Lu}, *$ : estimated) as reference standard were punched to disk shapes with the 

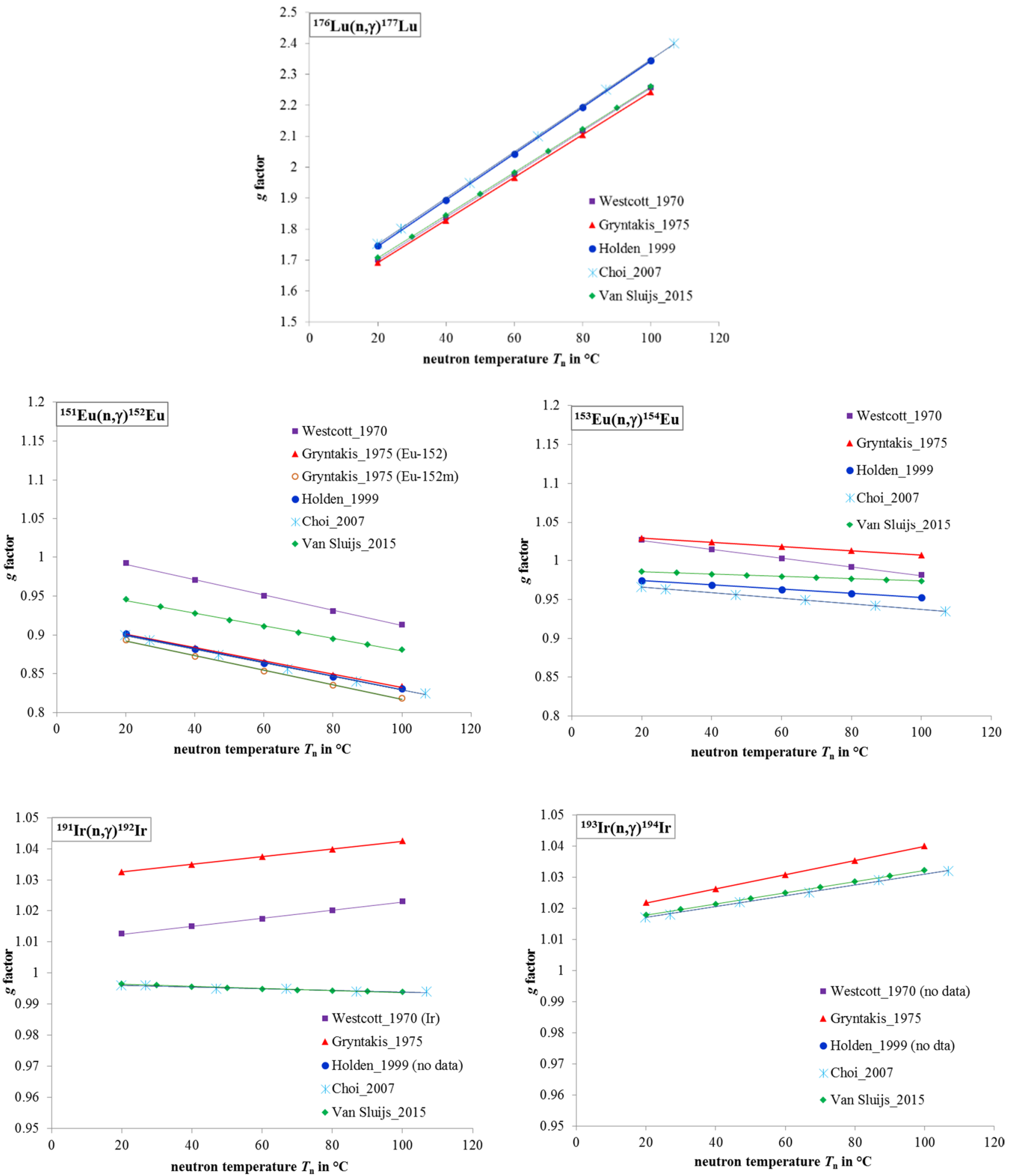

Figs. 1-5 $\mathrm{g}\left(T_{\mathrm{n}}\right)$ factors for the non-1/v isotopes of Lu, Eu and Ir from different data sources [8-11]

same diameter as the filter papers. Both foils had a thickness of $0.1 \mathrm{~mm}$.

For the in-situ determination of local temperature, irreversible thermometer labels from the company RS with a measuring range between $40{ }^{\circ} \mathrm{C}$ and $82{ }^{\circ} \mathrm{C}$ in different steps of $3{ }^{\circ} \mathrm{C}$ to $5{ }^{\circ} \mathrm{C}$ were chosen. The labels indicate the temperature by changing from white/grey to black permanently. The sensitivity tolerance and the response time are $\pm 1{ }^{\circ} \mathrm{C}$ 


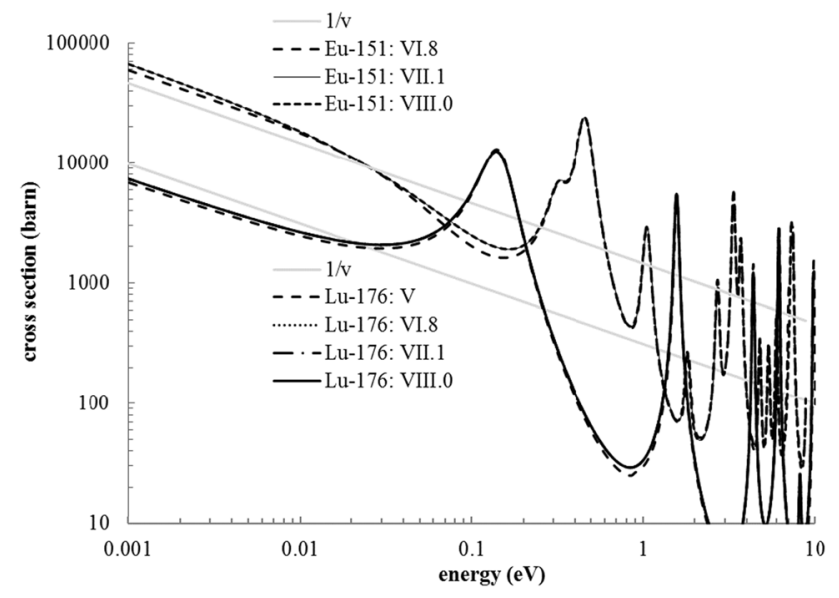

Fig. 6 neutron cross section for ${ }^{176} \mathrm{Lu}$ and ${ }^{151} \mathrm{Eu}$ in the ENDF database

and $1 \mathrm{~min}$, respectively [21]. Standards, comparators and thermometer labels had almost exactly the same geometry and were packed side by side together in the irradiation capsules, so that the influence of the flux gradients could be minimized effectively.

The research reactor FRM II has a compact core with highly enriched uranium located in the centre of the moderator tank filled with heavy water. The prepared standards were irradiated in four positions with different neutron fluxes from $3.5 \mathrm{E} 12$ to $4.4 \mathrm{E} 13 \mathrm{~cm}^{-2} \mathrm{~s}^{-1}$ and $f$ values from 3500 to 6500. The irradiation durations varied from $10 \mathrm{~min}$ to $1 \mathrm{~h}$.

All standards including the Au comparators were measured at $25 \mathrm{~cm}$ on two HPGe detectors with relative efficiencies of $27-34 \%$. The gamma counting was performed using Genie2000 (Mirion) spectroscopy software. The uncertainties of counting statistics were less than $0.5 \%$ for most gamma lines and the spectrometer dead time was always below $1 \%$ except for the ${ }^{152 \mathrm{~m}} \mathrm{Eu}$ measurements. Thus, the pulse pile-up effect was well within the correction capabilities of the spectrometer and led to negligible error. The first measurements were carried out at the same or the next day after the irradiation to determine the short-lived nuclides ${ }^{194} \mathrm{Ir}$ and ${ }^{177} \mathrm{Lu}$ and after three days for ${ }^{152 \mathrm{~m}} \mathrm{Eu}$ to reduce the count rate. The long-lived nuclides were measured at least two weeks later.

The full-energy peak efficiencies at $25 \mathrm{~cm}$ on the detectors were calibrated by using a multiple radionuclide standard solution QCY48 from Eckert \& Ziegler, which was pipetted on a filter paper with a diameter of $16 \mathrm{~mm}$. The uncertainties of standards used for the calibration were $2.3 \%$ to $3.5 \%$. All standard samples, monitors used for the $k_{0}$ determination and the QCY standard had exactly the same geometry and were measured at the same distance, so any systematic errors could be minimized, because for each detector only one efficiency curve was used and it was not necessary to do the calculation for the solid angles.

\section{Results}

The temperature measurements with the thermometer labels showed a local temperature range from ca. $40{ }^{\circ} \mathrm{C}$ to $55^{\circ} \mathrm{C}$ $\left(41.5 \pm 1.5^{\circ} \mathrm{C}, 41.5 \pm 1.5^{\circ} \mathrm{C}, 47.5 \pm 1.5^{\circ} \mathrm{C}\right.$ and $\left.54 \pm 3{ }^{\circ} \mathrm{C}\right)$ in the irradiation positions ( 3 rabbit channels RPA2, 3, 5 and 1 fishing position JBE70, respectively) chosen for the $k_{0}$ determination. These results were in accordance with the temperatures monitored by the reactor control system at different places in the reactor. A detailed description of the in situ temperature measurement can be found in another publication [7]. The $g\left(T_{\mathrm{n}}\right)$ factors were calculated according
Table 2 The coefficients of the linear approximation used for the calculation of $g\left(T_{\mathrm{n}}\right)$ factors in this work

\begin{tabular}{|c|c|c|c|c|c|c|}
\hline Nuclide year & Coefficient & $\begin{array}{l}\text { Westcott [3] } \\
1970\end{array}$ & $\begin{array}{l}\text { Gryntakis [8] } \\
1975\end{array}$ & $\begin{array}{l}\text { Holden [9] } \\
1999\end{array}$ & $\begin{array}{l}\text { Choi [10] } \\
2007\end{array}$ & $\begin{array}{l}\text { Sluijs [11] } \\
2015\end{array}$ \\
\hline \multirow{3}{*}{$\begin{array}{l}\text { Data library } \\
{ }^{176} \mathrm{Lu}\end{array}$} & & BNL-325 & diverse & ENDF/B-VI.4 & EAF-99 & ENDF/B-VII.1 \\
\hline & $a_{0}$ & 1.560 & 1.552 & $1.594 *$ & 1.602 & 1.569 \\
\hline & $a_{1}$ & 6.966 & 6.892 & $7.488 *$ & 7.451 & 6.910 \\
\hline${ }^{151} \mathrm{Eu}$ & $a_{0}$ & 1.011 & 0.9180 & 0.9177 & 0.9158 & 0.9604 \\
\hline$\left({ }^{152} \mathrm{Eu}\right)$ & $a_{1}$ & -0.9875 & -0.8575 & -0.8835 & -0.8664 & -0.8107 \\
\hline${ }^{151} \mathrm{Eu}$ & $\mathrm{a}_{0}$ & & 0.9110 & & & \\
\hline$\left({ }^{152 \mathrm{~m}} \mathrm{Eu}\right)$ & $a_{1}$ & & -0.9410 & & & \\
\hline \multirow[t]{2}{*}{${ }^{153} \mathrm{Eu}$} & $\mathrm{a}_{0}$ & 1.037 & 1.034 & 0.9794 & 0.9727 & 0.9886 \\
\hline & $a_{1}$ & -0.5610 & -0.2700 & -0.2725 & -0.3537 & -0.1485 \\
\hline \multirow[t]{2}{*}{${ }^{191} \operatorname{Ir}$} & $\mathrm{a}_{0}$ & 1.010 & 1.030 & & 0.9965 & 0.9970 \\
\hline & $a_{1}$ & 0.1290 & 0.1235 & & -0.0252 & -0.0328 \\
\hline \multirow[t]{2}{*}{${ }^{193} \operatorname{Ir}$} & $a_{0}$ & 1.010 & 1.017 & & 1.014 & 1.014 \\
\hline & $a_{1}$ & 0.1290 & 0.2270 & & 0.1748 & 0.1800 \\
\hline
\end{tabular}

* ENDF/B-V.1 
to Eq. 5 using the parameters given in Table 2 and the measured local temperatures of each irradiation.

The $k_{0}$ values shown in Table 3 were determined using Eq. 4 with different selected $g\left(T_{\mathrm{n}}\right)$ factors for a well-aimed comparison with the literature values $[4,15,16,18]$. The values are averages from at least 8 measurements. The $g\left(T_{\mathrm{n}}\right)$ factors by Gryntakis and Kim were used to determine the $k_{0}$ values for ${ }^{152} \mathrm{Eu}$ in the early time of $k_{0}$ NAA [2, 4]. Holden's data were mentioned in the literature [16] and used for the determination of the $k_{0}$ of $\mathrm{Lu}$ and $\mathrm{Eu}$ in 2016 [15]. This work is the first to use the $g\left(T_{\mathrm{n}}\right)$ of Van Sluijs et al. to determine $k_{0}$ values. For ${ }^{154} \mathrm{Eu},{ }^{192} \mathrm{Ir}$ and ${ }^{194} \mathrm{Ir}$, the $k_{0}$ values were also determined with $g=1$, as was done in the previous published works.

For convenience, in Table 3 and in the following text, abbreviations, e.g. Holden $k_{0}$ values, will be used to refer to the $k_{0}$ values calculated with Holden's $g\left(T_{\mathrm{n}}\right)$ factors and so on.

\section{Comparison with earlier $\boldsymbol{k}_{\mathbf{0}}$ factor determinations}

Cimpan and Kennedy measured $k_{0}$ values for $\mathrm{Lu}$ and $\mathrm{Eu}$ in 2016 [15]; these data were used in the comparison next to earlier recommended data. The measurements presented

Table $3 k_{0}$ values obtained using different $g\left(T_{\mathrm{n}}\right)$ factors from Gryntakis [8], Holden [9], Van Sluijs [11] and $g=1$ in this work compared with literature values $[4,16,18]$ and recalculated data from [15]

\begin{tabular}{|c|c|c|c|c|c|c|c|c|c|c|c|}
\hline & \multirow[t]{2}{*}{ Energy (keV) } & \multicolumn{5}{|c|}{$k_{0}$, this work } & \multicolumn{2}{|c|}{$k_{0}$, recommended } & \multicolumn{3}{|c|}{$k_{0},[15]$ recalculated } \\
\hline & & Gryntakis & Holden & Van Sluijs & $g=1$ & $\mathrm{~s}, \%$ & (tentative) & $\mathrm{s}, \%$ & Gryntakis & Van Sluijs & $\mathrm{s}, \%$ \\
\hline \multirow[t]{10}{*}{${ }^{152} \mathrm{Eu}$} & 121.8 & 12.1 & 12.2 & 11.5 & & 1.7 & 12.8 & 0.8 & 13.3 & 12.5 & 3 \\
\hline & 244.7 & 3.40 & 3.43 & 3.24 & & 1.7 & 3.44 & 0.3 & 3.49 & 3.27 & 2 \\
\hline & 344.3 & 11.7 & 11.8 & 11.1 & & 1.7 & 11.9 & 0.9 & 12.3 & 11.51 & 2 \\
\hline & 443.9 & 1.41 & 1.42 & 1.34 & & 1.7 & 1.39 & 1.2 & 1.48 & 1.39 & 2 \\
\hline & 778.9 & 5.73 & 5.76 & 5.45 & & 1.7 & 5.70 & 0.8 & 6.06 & 5.68 & 2 \\
\hline & 867.4 & 1.87 & 1.89 & 1.78 & & 1.8 & 1.88 & 0.9 & 1.99 & 1.86 & 2 \\
\hline & 964.1 & 6.48 & 6.52 & 6.17 & & 1.8 & 6.46 & 0.4 & 6.89 & 6.46 & 2 \\
\hline & 1085.9 & 4.49 & 4.52 & 4.27 & & 1.9 & 4.57 & 0.4 & 4.73 & 4.44 & 2 \\
\hline & 1112.1 & 5.97 & 6.01 & 5.68 & & 2.0 & 6.06 & 0.8 & 6.40 & 6.00 & 2 \\
\hline & 1408.0 & 9.35 & 9.41 & 8.90 & & 2.3 & 9.36 & 0.6 & 9.67 & 9.06 & 2 \\
\hline \multirow[t]{4}{*}{${ }^{152 \mathrm{~m}} \mathrm{Eu}$} & 121.8 & 1.64 & 1.61 & 1.56 & & 1.8 & (1.48) & - & 1.81 & 1.68 & 3 \\
\hline & 344.3 & 0.534 & 0.520 & 0.508 & & 1.9 & $(0.498)$ & - & 0.585 & 0.543 & 2 \\
\hline & 841.6 & 3.23 & 3.17 & 3.07 & & 1.8 & (3.02) & - & 3.51 & 3.26 & 2 \\
\hline & 963.4 & 2.67 & 2.62 & 2.54 & & 1.8 & $(2.49)$ & - & 2.88 & 2.67 & 2 \\
\hline \multirow[t]{7}{*}{${ }^{154} \mathrm{Eu}$} & 248.0 & 0.155 & 0.164 & 0.161 & 0.158 & 1.8 & $(0.155)$ & - & $0.151^{\mathrm{a}}$ & $0.156^{\mathrm{b}}$ & 2 \\
\hline & 591.8 & 0.110 & 0.117 & 0.115 & 0.112 & 2.3 & 0.108 & 1.5 & $0.115^{\mathrm{a}}$ & $0.119^{\mathrm{b}}$ & 2 \\
\hline & 723.3 & 0.446 & 0.471 & 0.464 & 0.455 & 1.8 & 0.446 & 1.5 & $0.471^{\mathrm{a}}$ & $0.488^{b}$ & 2 \\
\hline & 756.9 & 0.104 & 0.110 & 0.109 & 0.106 & 2.6 & (0.108) & - & $0.119^{\mathrm{a}}$ & $0.124^{\mathrm{b}}$ & 2 \\
\hline & 873.3 & 0.272 & 0.287 & 0.283 & 0.277 & 2.0 & 0.272 & 1.4 & $0.293^{\mathrm{a}}$ & $0.304^{b}$ & 2 \\
\hline & 996.4 & 0.234 & 0.248 & 0.244 & 0.239 & 2.0 & $(0.230)$ & - & $0.239^{\mathrm{a}}$ & $0.248^{\mathrm{b}}$ & 2 \\
\hline & 1274.4 & 0.790 & 0.835 & 0.822 & 0.806 & 2.0 & 0.777 & 1.1 & $0.813^{\mathrm{a}}$ & $0.843^{\mathrm{b}}$ & 2 \\
\hline \multirow[t]{2}{*}{${ }^{177} \mathrm{Lu}$} & 112.9 & 0.0398 & 0.0383 & 0.0394 & & 3.1 & 0.0415 & - & $0.0421^{\mathrm{c}}$ & $0.0446^{\mathrm{d}}$ & 4 \\
\hline & 208.4 & 0.0706 & 0.0680 & 0.0699 & & 2.6 & 0.0714 & - & $0.0716^{\mathrm{c}}$ & $0.0758^{\mathrm{d}}$ & 3 \\
\hline \multirow[t]{4}{*}{${ }^{192} \mathrm{Ir}$} & 296.0 & 1.09 & - & 1.14 & 1.13 & 1.7 & 1.14 & 1.2 & & & \\
\hline & 308.5 & 1.13 & - & 1.18 & 1.17 & 1.7 & 1.18 & 1.2 & & & \\
\hline & 316.5 & 3.14 & - & 3.27 & 3.25 & 1.7 & 3.26 & 1.2 & & & \\
\hline & 468.1 & 1.78 & & 1.85 & 1.84 & 1.7 & 1.87 & 1.2 & & & \\
\hline \multirow[t]{5}{*}{${ }^{194} \mathrm{Ir}$} & 293.5 & 0.0199 & - & 0.0201 & 0.0204 & 1.8 & 0.0204 & 1.1 & & & \\
\hline & 328.4 & 0.103 & - & 0.104 & 0.106 & 1.7 & 0.105 & 1.0 & & & \\
\hline & 645.1 & 0.00924 & - & 0.00929 & 0.00948 & 1.8 & 0.00960 & 1.1 & & & \\
\hline & 938.7 & 0.00455 & - & 0.00458 & 0.00467 & 2.0 & 0.00481 & 1.7 & & & \\
\hline & 1150.8 & 0.00462 & _- & 0.00465 & 0.00474 & 1.9 & 0.00476 & 1.1 & & & \\
\hline
\end{tabular}

${ }^{\mathrm{a} C}$ Calculated with $g\left(T_{\mathrm{n}}\right)=1$ and $Q_{0}=5.1,{ }^{\mathrm{b}}$ Calculated with $g\left(T_{\mathrm{n}}\right)=1$ and $Q_{0}=3.95,{ }^{\mathrm{c} C a l c u l a t e d ~ w i t h ~ H o l d e n ~} g\left(T_{\mathrm{n}}\right)$ factor and $Q_{0}=3.2$, ${ }^{\mathrm{d}} \mathrm{Calculated}$ with Van Sluijs $g\left(T_{\mathrm{n}}\right)$ factor and $Q_{\mathrm{E}}=2.84$ at the mean $T_{\mathrm{n}}$ of $36^{\circ} \mathrm{C}$ 
in [15] required significant corrections for epithermal neutrons $(f=18$ and $f=52)$ and the neutron temperatures in [15], averaging $35{ }^{\circ} \mathrm{C}$ for ${ }^{152} \mathrm{Eu}, 30{ }^{\circ} \mathrm{C}$ for ${ }^{152 \mathrm{~m}} \mathrm{Eu}$ and $36{ }^{\circ} \mathrm{C}$ for ${ }^{177} \mathrm{Lu}$, were derived from the estimated temperature of the moderator surrounding the samples. In Table 3 the $k_{0}$ values measured in [15] have been recalculated using updated data. For ${ }^{152} \mathrm{Eu},{ }^{152 \mathrm{~m}} \mathrm{Eu},{ }^{154} \mathrm{Eu}$ and ${ }^{177} \mathrm{Lu}$ the detection efficiencies needed for the calculation of the $k_{0}$ values were improved with new estimates of gamma attenuation in the samples. This reduced the $k_{0}$ values by $2.4 \%$ at $121.8 \mathrm{keV}$ and by $0.9 \%$ at $1408 \mathrm{keV}$. For ${ }^{152} \mathrm{Eu}$ and ${ }^{152 \mathrm{~m}} \mathrm{Eu}$ the $k_{0}$ values were recalculated with the Gryntakis $g\left(T_{\mathrm{n}}\right)$ factors for better comparison with the values from [4], while the ${ }^{177} \mathrm{Lu} k_{0}$ values are calculated with the Holden $g\left(T_{n}\right)$ factors and the measured $Q_{0}$ value of 3.2 as they were in [15]. For ${ }^{154} \mathrm{Eu}$ the $k_{0}$ values were calculated with $g\left(T_{\mathrm{n}}\right)=1$ as was done previously $[2,15]$ and the correction for epithermal activation was carried out using the $Q_{0}$ value of 5.1 measured in [15] and also with the $Q_{0}$ value of 3.95 and effective resonance energy of $8.0 \mathrm{eV}$ calculated recently by Van Sluijs [17]. For ${ }^{152} \mathrm{Eu}$, ${ }^{152 \mathrm{~m}} \mathrm{Eu}$, and ${ }^{177} \mathrm{Lu}$ the $k_{0}$ values were calculated a second time using the parameters $g\left(T_{\mathrm{n}}\right), Q_{\mathrm{E}}\left(\alpha, T_{\mathrm{n}}\right)$ and $d Q(\alpha)$ of Van Sluijs in the recently published [20] extended version of the modified Høgdahl convention. The formula from [20] used to calculate these $k_{0}$ values corrects the non- $1 / v$ nuclide for epithermal neutron activation using a value of $Q_{\mathrm{E}}\left(\alpha, T_{\mathrm{n}}\right)$ calculated from tables of measured $\sigma(E)$ rather than a measured value of $Q_{0}$

$k_{0}=\frac{\left(\frac{N_{p}}{S D C W \rho t_{m}}\right)}{\left(\frac{N_{p}}{S D C w t_{m}}\right)^{*}} \frac{f+Q_{0}(\alpha)^{*}}{g\left(T_{n}\right)(f-d Q(\alpha))+Q_{E}\left(\alpha, T_{n}\right)} \frac{\varepsilon_{p}^{*}}{\varepsilon_{p}}$

where $(*)$ designates the ${ }^{197} \mathrm{Au}$ comparator which is treated as a $1 / v$-nuclide.

\section{Uncertainties}

The uncertainty of the activity calculation includes the uncertainties of net peak areas $N_{\mathrm{p}}(<0.5 \%$ for the main gamma lines) and sample weights $W(<0.1 \%)$. These give a statistical uncertainty of maximum $0.5 \%$ for the calculation of the $k_{0}$ values using Eq. 4 . All other uncertainties related to the irradiation and the gamma counting such as the uncertainties of the time factors were not taken into account.

Furthermore, the main contributions for the systematic uncertainty are the concentration $\rho$ of the standards $(1.2 \%$ for $\mathrm{Au}$ and $0.5 \%$ for the rest) and the efficiency ratio between the gamma-energy of the comparator ${ }^{198} \mathrm{Au}$ at $411.8 \mathrm{keV}$ and the gamma-energies, whose $k_{0}$ value should be determined. If the same efficiency curve is used, the efficiencies are correlated, and therefore the systematic errors of the efficiency calibration can be reduced significantly. According the approach of Smodiš and Bucar [22] the uncertainty of the efficiency ratio can be estimated to be lower than $1 \%$ for the gamma-lines with energy near the monitor energy of $411.8 \mathrm{keV}$ and $1.8 \%$ for the higher energies up to $1408 \mathrm{keV}$, which is the highest gamma-energy concerned in this work.

In addition, the contribution of the $g$ factor in Eq. 4 to the total uncertainty is dependent on the uncertainty of the temperature determined by using the thermometer labels and the slope of the chosen $g\left(T_{n}\right)$ function. Due to the discrete levels on the thermometer labels, the uncertainty of the temperature could be estimated as the half of the detection steps. That was $1.5^{\circ} \mathrm{C}$ for the temperature range below $49^{\circ} \mathrm{C}$ and $2.5{ }^{\circ} \mathrm{C}$ for the higher range [21] and created an uncertainty of the $g$ factor less than $1 \%$ for ${ }^{177} \mathrm{Lu}$ and less than $0.2 \%$ for the other nuclides. The total uncertainty for the $k_{0}$ value can be calculated with a simple propagation formula:

$\frac{\Delta k_{0}}{k_{0}(x)}=\sqrt{\left(\frac{\Delta \rho}{\rho}\right)_{\text {Au }}^{2}+\left(\frac{\Delta \rho}{\rho}\right)_{x}^{2}+\left(\frac{\Delta N_{p}}{N_{p}}\right)_{\text {Au }}^{2}+\left(\frac{\Delta N_{p}}{N_{p}}\right)_{x}^{2}+\left(\frac{\Delta \varepsilon_{p}}{\varepsilon_{p}}\right)^{2}+\left(\frac{\Delta g}{g}\right)^{2}}$

In the extended Høgdahl formalism (Eq. 2) the $g\left(T_{\mathrm{n}}\right)$ factor of $\mathrm{Au}$ is set to 1. Actually, depending on the selection of the different data sources, the $g\left(T_{n}\right)$ factor of Au varies between 1.005 and 1.007 in the temperature range in this work. For a reactor with small $f$, this tiny deviation is much smaller than the contribution of the activation with epi-thermal neutrons $\left(Q_{0} / f\right)$. However, for reactors with large $f$, the part of the epi-thermal neutron reaction is negligible, and the small deviation of the $g\left(T_{\mathrm{n}}\right)$ factor of Au can be transferred to the $k_{0}$ determination proportionally. Therefore, all $k_{0}$ values in Table 3 should be theoretically adjusted upwards by about $0.5 \%$ if they are to be compared to previously measured values such as the ${ }^{152} \mathrm{Eu}$ and ${ }^{152 \mathrm{~m}} \mathrm{Eu} k_{0}$ values presented in [4] which were calculated using the Westcott formalism. However, in the extended version of the modified Høgdahl convention $[14,20]$ this factor of 1.005 is not used.

\section{Discussion}

The starting point for the $k_{0}$ determination for non- $1 / v$ nuclides is the measurement of the neutron temperature. According to Eq. 5 and Table 2, the whole temperature range of about $15 \mathrm{~K}$ determined in this work can create only a small change of the $g$ factors. It is about $5 \%$ for ${ }^{176} \mathrm{Lu}, 1.5 \%$ for ${ }^{151} \mathrm{Eu}$ and less than $1 \%$ for the rest. That means that even a large error in the temperature determination, say $3 \mathrm{~K}$, has a small influence on the measured $k_{0}$ values compared to the discrepancies between the different $g\left(T_{\mathrm{n}}\right)$ factors.

Looking first at the results in Table 3 for ${ }^{152} \mathrm{Eu}$, the Gryntakis $k_{0}$ values determined in this work have good agreement, usually within $2 \%$, with the recommended values. This good agreement can be understood easily because the same 
$g\left(T_{\mathrm{n}}\right)$ factors were used for the calculation of the recommended values measured in the 1980s [2, 4], and it appears to confirm that the two sets of measurements are accurate. Only the value for the $121.8 \mathrm{keV}$ gamma-ray is about $5 \%$ lower, possibly due to the interference with the $123 \mathrm{keV}$ line of ${ }^{154} \mathrm{Eu}$. The Van Sluijs $k_{0}$ values are generally about $5 \%$ lower, evidently because of the 5\% higher Van Sluijs $g\left(T_{\mathrm{n}}\right)$ factors.

All gamma lines of ${ }^{152 \mathrm{~m}} \mathrm{Eu}$ suffer interference from ${ }^{152} \mathrm{Eu}$. The contributions of the long-lived isotope ${ }^{152} \mathrm{Eu}$ to the net peak areas of the interfered gamma lines of ${ }^{152 \mathrm{~m}}$ Eu were corrected carefully. But it can still be found that Gryntakis and Holden $k_{0}$ values for ${ }^{152 \mathrm{~m}} \mathrm{Eu}$ are $7 \%$ and $5 \%$ higher than the tentative values in the literature $[4,16,18]$, respectively. It is postulated here that the ${ }^{152 \mathrm{~m}} \mathrm{Eu} k_{0}$ values of the present work are an improvement over the values of $[4,16]$ because of improved counting loss corrections with the modern gammaray spectrometers used.

${ }^{154} \mathrm{Eu}$ was always treated as a $1 / v$ nuclide in the $k_{0}$ databases. The $k_{0}$ values of the present work in Table 3 calculated with $g=1$, except for the weak $756.9 \mathrm{keV}$ line, are all $1 \%$ to $4 \%$ greater than the recommended values, suggesting a $2 \%$ or $3 \%$ systematic difference. Any of the $k_{0}$ values for the $756.9 \mathrm{keV}$ gamma-ray may be up to $10 \%$ too high due to the possible presence of interfering gamma-rays at $756 \mathrm{keV}$, including the $756.1 \mathrm{keV}$ gamma-ray from ${ }^{152} \mathrm{Eu}$. If the $k_{0}$ values of the present work for the stronger high-energy gammarays are compared to those measured in [15] corrected for epithermal neutrons using the measured $Q_{0}$ value of 5.1, the values of [15] are on average $2.6 \%$ higher. If the comparison is done with the values of [15] corrected for epithermal neutrons using the $Q_{0}$ value of 3.95 calculated in [17] from $\sigma(E)$, then the average difference rises to $6.3 \%$. This change from $2.6 \%$ difference to $6.3 \%$ illustrates the uncertainty in correcting for epithermal neutrons, which can be eliminated by using a very well thermalized neutron spectrum as was done in this work.

For the highly non- $1 / v$ nuclides ${ }^{152} \mathrm{Eu},{ }^{152 \mathrm{~m}} \mathrm{Eu}$, and ${ }^{177} \mathrm{Lu}$ the $k_{0}$ values of the present work were compared to those of [15]. Only the more interference-free high-energy gamma lines were considered, and the comparison was done with the $k_{0}$ values calculated with the Van Sluijs [17] $g\left(T_{\mathrm{n}}\right)$ factors. On average, the $k_{0}$ values of [15] were found to be $4.0 \%$ higher for ${ }^{152} \mathrm{Eu}, 5.7 \%$ higher for ${ }^{152 \mathrm{~m}} \mathrm{Eu}$, and $8.4 \%$ higher for the $208.4 \mathrm{keV}$ gamma-ray of ${ }^{177} \mathrm{Lu}$. For ${ }^{152} \mathrm{Eu}$ the average difference rises from $4.0 \%$ to $5.6 \%$, if the comparison is made with Gryntakis $k_{0}$ values because in this case the Gryntakis $k_{0}$ values of [15] were corrected for epithermal activation using the measured $Q_{0}$ value of 0.3 rather than the $Q_{E}$ value of 1.48 calculated by Van Sluijs [20].

The reasons for these differences are unknown but they suggest that $k_{0}$ NAA with non- $1 / v$ nuclides may continue to have uncertainty of $4 \%$ to $8 \%$ at different research reactors until further measurements are performed. The irradiation channels at the FRM II reactor are surrounded by heavy water (or light water in one position) while those at the SLOWPOKE reactor of [15] are surrounded by beryllium or light water and beryllium. Does a beryllium moderator change the shape of the thermal neutron spectrum so that the available $g\left(T_{\mathrm{n}}\right)$ calculations are no longer valid?

The Lu standards made with the ICP-standard solution and the LuAl-alloy standards showed the same results in this work. The new $k_{0}$ values determined with $g\left(T_{\mathrm{n}}\right)$ factors by Gryntakis and Van Sluijs are 2\% lower than the recommended values for the $208 \mathrm{keV}$, but 4-5\% lower for the $112 \mathrm{keV}$ line. The Holden's $k_{0}$ values are much lower. The reason for lower $k_{0}$ values at the lower energy $112 \mathrm{keV}$ might be the uncertainty of the efficiency calibration in this region. The calibration curve on the left side of the turning point has generally an extreme curvature and the nuclides in the QCY standards used for the calibration according to the certification have larger uncertainty, up to $3.5 \%$, in this region than the nuclides with higher gamma energy.

Until now, the recommended $k_{0}$ values for ${ }^{177} \mathrm{Lu}$ have remained unchanged since they were calculated in the $1980 \mathrm{~s}$ [2]. By definition, the $k_{0}$ value (relative to $\mathrm{Au}$ ) is given as follows:

$k_{0, A u}=\frac{\left(\frac{\theta \sigma_{0} e_{\gamma}}{M}\right)}{\left(\frac{\theta \sigma_{0} e_{\gamma}}{M}\right)_{\mathrm{Au}}}$

where $\theta$ is the fractional isotopic abundance, $\sigma_{0}$ is the (n, $\left.\gamma\right)$ cross-section at neutron velocity of $2200 \mathrm{~m} \mathrm{~s}^{-1}, e \gamma$ is the absolute gamma-intensity, $M$ is the molar mass of the target element.

New evaluations show the absolute gamma intensity $e \gamma$ $5.6 \%$ lower for the main gamma line at $208 \mathrm{keV}$ and 3\% lower for the second gamma line at $112.9 \mathrm{keV}$ compared to the old values used for the calculation of the recommended $k_{0}$ value $[23,24]$. These new $e \gamma$ values have progressively been accepted in many databases worldwide [25-27]. New $k_{0}$ values for ${ }^{177} \mathrm{Lu}$ were calculated in this work with the new data shown in Table 4. They are lower than before and, for the $208 \mathrm{keV}$ gamma-ray, the new calculated value is $5.7 \%$ lower than the old recommended value and $3.7 \%$ lower than the Van Sluijs $k_{0}$ value measured in the present work. These large variations in measured and calculated $k_{0}$ values for ${ }^{177} \mathrm{Lu}$ indicate a need for a new evaluation of the recommended $k_{0}$ values and new measurements at other research reactors.

For a long time ${ }^{192} \mathrm{Ir}$ was considered as a non- $1 / v$ nuclide. However, in the current version of the $k_{0}$ database [18], updated for ${ }^{192} \mathrm{Ir}$ and ${ }^{194} \mathrm{Ir}$ in 2015 , the new $k_{0}$ values of ${ }^{192} \mathrm{Ir}$ are recommended after an evaluation of measurements at three laboratories in 2014 [12,13] where it was assumed 
Table 4 Different nuclear data used to calculate the $k_{0}$ values of ${ }^{177} \mathrm{Lu}$

\begin{tabular}{lllllllll}
\hline & $M(\mathrm{~g} / \mathrm{mol})$ & $\theta(\%)$ & $\sigma_{0}(\mathrm{barn})$ & $E \gamma(\mathrm{keV})$ & $e \gamma($ old $)(\%)[2]$ & $E \gamma($ new $)(\%)[23]$ & $k_{0}$, rec.* [16] & $k_{0}($ new cal.)* \\
\hline${ }^{197} \mathrm{Au}$ & 196.97 & 100 & 98.66 & 411.8 & 95.62 & - & 1 & - \\
${ }^{176} \mathrm{Lu}$ & 174.97 & 2.59 & 2100 & 112.9 & $6.4(4)$ & $6.20(7)$ & $0.0415(26)$ & $0.0402(5)$ \\
& & & & 208.4 & $11.0(4)$ & $10.38(7)$ & $0.0714(26)$ & $0.0673(5)$ \\
\hline
\end{tabular}

*rec.: recommended values, new cal.: new calculated values in this work, $E \gamma$ : gamma energy

that $g\left(T_{\mathrm{n}}\right)$ was equal to unity and no temperature correction was performed. The new calculation by Van Sluijs et al. [11] confirmed this assumption that $g\left(T_{\mathrm{n}}\right)$ factors for ${ }^{192} \mathrm{Ir}$ are very close to 1 . The $k_{0}$ values of ${ }^{192}$ Ir determined in this work have good agreement with the recommended values, whether they are calculated with these latest $g\left(T_{\mathrm{n}}\right)$ factors or with $g\left(T_{\mathrm{n}}\right)$ equal to 1 . For ${ }^{194} \mathrm{Ir}$, the $k_{0}$ values of the present work, calculated with the latest $g\left(T_{\mathrm{n}}\right)$ factors or with $g\left(T_{\mathrm{n}}\right)$ equal to 1 , are also in good agreement with the recommended values.

As shown in this work, the determination of the $k_{0}$ values is dependent on the choice of the $g\left(T_{\mathrm{n}}\right)$ factors; the $k_{0}$ value obtained depends on which $g\left(T_{\mathrm{n}}\right)$ function was used. However, for the determination of concentrations with $k_{0}$ NAA, the product of $k_{0}$ and $g\left(T_{\mathrm{n}}\right)$ plays the key role, see Eq. 3. Thus it doesn't matter which $k_{0}$ values are used as long as the same $g\left(T_{\mathrm{n}}\right)$ function is used for the determination of a concentration as was used when the $k_{0}$ value was determined. Then the absolute magnitude of the $g\left(T_{\mathrm{n}}\right)$ factor cancels and there is only a small temperature correction using $g\left(T_{\mathrm{n}}\right)$. Even though different $g\left(T_{\mathrm{n}}\right)$ calculations may differ by up to $5 \%$, the uncertainty of $k_{0}$ NAA measurements due to the temperature correction with a consistent $g\left(T_{\mathrm{n}}\right)$ will usually be less than $1 \%$.

\section{Conclusions}

The present work confirmed the recommended $k_{0}$ values for ${ }^{152} \mathrm{Eu},{ }^{154} \mathrm{Eu}$ and ${ }^{177} \mathrm{Lu}$ using the $g\left(T_{\mathrm{n}}\right)$ factors by Gryntakis and Kim. For ${ }^{152 \mathrm{~m}} \mathrm{Eu}$, the $k_{0}$ values of the present work are about $7 \%$ higher than the tentative values of the recommended $k_{0}$ database, possibly due to improved counting loss corrections with modern gamma-ray spectrometers; the values measured in [15] are even higher. The ${ }^{152 \mathrm{~m}} \mathrm{Eu} k_{0}$ values should be measured again at other laboratories.

The present results for ${ }^{192} \mathrm{Ir}$ and ${ }^{194} \mathrm{Ir}$ are consistent with the new recommended $k_{0}$ values of 2015 and they confirm that the both Ir isotopes can be treated as $1 / v$ nuclides and no corrections with $g\left(T_{\mathrm{n}}\right)$ factors are necessary.

The $k_{0}$ values of ${ }^{177} \mathrm{Lu}$ were calculated using new nuclear data. They are 3-6\% less than the recommended values calculated in the 1980s. The measured $k_{0}$ values of the present work showed the same trend. Perhaps an update of the recommended $k_{0}$ values for ${ }^{177} \mathrm{Lu}$ should be considered.

The present work deals with the determination of $k_{0}$ factors in the ideal case of a highly thermalised neutron flux where the epithermal contribution is negligible. For practical use in not so well-thermalised conditions, the determination, evaluation and recommendation of "epithermal-related" data such as $\bar{E}_{r}, Q_{0}$ or $s_{0}$ should be an additional task to be undertaken.

In this work the situation of the various calculated $g\left(T_{\mathrm{n}}\right)$ factors has been clarified. The $g\left(T_{\mathrm{n}}\right)$ factors calculated by Van Sluijs et al. using more recent $\sigma(E)$ data are likely more accurate than the old factors. It is therefore recommended that they be used for future $k_{0}$ NAA work with non- $1 / v$ nuclides with the extended Høgdahl formalism, but they must be used with $k_{0}$ values adjusted for these same $g\left(T_{n}\right)$ factors. It has been shown that the influence of the neutron temperature measurement on the $k_{0}$ determination for all non- $1 / v$ nuclides is rather small; the estimation of neutron temperatures using thermometer labels as in this work or by moderator thermocouple readings as in [15] are of sufficient accuracy. More important is the choice of suitable calculated $g\left(T_{\mathrm{n}}\right)$ factors. Different $g\left(T_{\mathrm{n}}\right)$ factors lead to different $k_{0}$ values.

Finally, there is a general recommendation: the $k_{0}$ values for non- $1 / v$ nuclides should be used in $k_{0}$ NAA only in combination with the $g\left(T_{\mathrm{n}}\right)$ factors which were used for the determination of these $k_{0}$ values.

Funding Open Access funding enabled and organized by Projekt DEAL.

Open Access This article is licensed under a Creative Commons Attribution 4.0 International License, which permits use, sharing, adaptation, distribution and reproduction in any medium or format, as long as you give appropriate credit to the original author(s) and the source, provide a link to the Creative Commons licence, and indicate if changes were made. The images or other third party material in this article are included in the article's Creative Commons licence, unless indicated otherwise in a credit line to the material. If material is not included in the article's Creative Commons licence and your intended use is not permitted by statutory regulation or exceeds the permitted use, you will need to obtain permission directly from the copyright holder. To view a copy of this licence, visit http://creativecommons.org/licenses/by/4.0/. 


\section{References}

1. Høgdahl O.T (1962) Neutron absorption in pile neutron activation analysis, Report MMPP-226-1

2. De Corte F (1987) The k0-standardization method: a move to the optimization of neutron activation analysis. Habil. Thesis, University of Gent, Belgium

3. Westcott CH (1960) Effective cross section values for well-moderated thermal reactor spectra, report CRRP-960 of the AECL-1101, Nov. 1, 1960 (reprinted 1970)

4. De Corte F, Simonits A, Bellemans F, Freitas MC, Jovanović S, Smodiš B, Erdmann G, Petri H, De Wispelaere A (1993) Recent advances in the $k_{0}$-standardization of neutron activation analysis: Extensions, applications, prospects. J Radioanal Nucl Chem 169:125-158

5. De Corte F, Bellemans F, De Neve P, Simonits A (1994) The use of a modified Westcott-formalism in the $\mathrm{k}_{0}$-standardization of NAA: The state of affairs. J Radioanal Nucl Chem 179:93-103

6. St-Pierre J, Kennedy G (2007) Corrections for neutron activation analysis with non- $1 / v$ nuclides using reactor moderator temperature readings. J Radioanal Nucl Chem 271:283-287

7. Li X (2020) In situ measurement of neutron temperature for the extended $k_{0}$ NAA at FRM II. J Radioanal Nucl Chem 326:1391-1397

8. Gryntakis EM, Kim JI (1975) Absorption, Activation and Fission $g\left(T_{\mathrm{n}}\right)$-Functions for non $1 / v$-Nuclides. Radiochim Acta 22:128-147

9. Holden NE (1999) Temperature dependence of the Westcott g-factor for neutron reactions in activation analysis. Pure Appl Chem 71:2309-2315

10. Choi HD, Trkov A (2007) Chap. 2, Nomenclature, Westcott $g_{w}$ factors and neutron spectral shape dependent formalism. In: Database of prompt gamma rays from slow neutron capture for elemental analysis, IAEA, STI/PUB/1263

11. Van Sluijs R, Stopic A, Jacimovic R (2015) Evaluation of Westcott $g\left(T_{\mathrm{n}}\right)$-factors used in $k_{0}$-NAA for "non- $1 / v$ " (n, $\left.\gamma\right)$ reactions. J Radioanal Nucl Chem 306:579-587

12. Chilian C, Sneyers L, Vermaercke P, Kennedy G (2014) Measurement of $k_{0}$ and $Q_{0}$ values for iridium isotopes. J Radioanal Nucl Chem 300:609-613

13. Stopic A, Bennett JW (2014) Measurement of $k_{0}$ values for caesium and iridium. J Radioanal Nucl Chem 300:593-597
14. Van Sluijs R, Jacimovic R, Kennedy G (2014) A simplified method to replace the Westcott formalism in $k_{0}$-NAA using non1/v nuclides. J Radioanal Nucl Chem 300:539-545

15. Cimpan C, Kennedy G (2016) Measurement of $k_{0}$ and $Q_{0}$ values for lutetium and europium. J Radioanal Nucl Chem 309:173-178

16. De Corte F, Simonits A (2003) Recommended nuclear data for use in the $k_{0}$ standardization of neutron activation analysis. Atomic Data Nucl Data Tables 85:47-67

17. Van Sluijs R (2016) $Q_{0}$ 's and resonance energies used in $k_{0}$-NAA compared with estimations based on ENDF/B-VII.1 cross section data. J Radioanal Nucl Chem 309:219-228

18. $k_{0}$ database (2020) http://www.kayzero.com/k0naa/k0naaorg/ Nuclear_Data_SC/Entries/2020/8/24_Update_of_k0-database_I128_files/k0_database_2020_08_13.xls. Accessed 22 Sep 2020

19. Li X, Lierse von Gostomski C (2014) Applications of $k_{0}$ NAA at FRM II with high $f$ values. J Radioanal Nucl Chem 300:457-463

20. Van Sluijs R (2019) The Westcott convention converted in the extended version of the modified Høgdahl convention. J Radioanal Nucl Chem 319:1277-1282

21. RS Components, datasheet, https://docs.rs-online.com/f777/09007 66b815e4e41.pdf. Accessed 02 Sep 2020

22. Smodiš B, Bučar T (2014) Status of uncertainty assessment in $k_{0}$-NAA measurement: anything still missing? J Radioanal Nucl Chem 300:567-572

23. Kondev F.G (2002) Laboratoire National Henri Becquerel. http://www.nucleide.org/DDEP_WG/Nuclides/Lu-177_com.pdf. Accessed 15 Sep 2020

24. Kondev FG (2019) Nuclear Data Sheets for $A=177$. Nucl Data Sheets 159:1-412

25. Laboratoire National Henri Becquerel. http://www.nucleide.org/ Laraweb/index.php. Accessed $20 \mathrm{Jul} 2020$

26. Nuclear Data Center at KAERI. http://atom.kaeri.re.kr/. Accessed $20 \mathrm{Jul} 2020$

27. National Nuclear Data Center, Brookhaven National Laboratory https://www.nndc.bnl.gov/nudat2/. Accessed 20 Jul 2020

Publisher's Note Springer Nature remains neutral with regard to jurisdictional claims in published maps and institutional affiliations. 